\title{
Diagnosing the average spatio-temporal impact of convective systems - Part 1: A methodology for evaluating climate models
}

\author{
M. S. Johnston ${ }^{1,4}$, S. Eliasson ${ }^{2,4}$, P. Eriksson ${ }^{1}$, R. M. Forbes ${ }^{5}$, K. Wyser ${ }^{4}$, and M. D. Zelinka ${ }^{3}$ \\ ${ }^{1}$ Department of Earth and Space Sciences, Chalmers University of Technology, Gothenburg, Sweden \\ ${ }^{2}$ Department of Computer Science, Electrical and Space Engineering, Division of Space Technology, Luleå University of \\ Technology, Kiruna, Sweden \\ ${ }^{3}$ Program for Climate Model Diagnosis and Intercomparison, Lawrence Livermore National Laboratory, Livermore, \\ California, USA \\ ${ }^{4}$ Swedish Meteorological and Hydrological Institute, Norrköping, Sweden \\ ${ }^{5}$ European Centre for Medium-Range Weather Forecasts, Reading, UK
}

Correspondence to: M. S. Johnston (shejo284@gmail.com)

Received: 21 March 2013 - Published in Atmos. Chem. Phys. Discuss.: 23 May 2013

Revised: 4 October 2013 - Accepted: 4 November 2013 - Published: 12 December 2013

\begin{abstract}
An earlier method to determine the mean response of upper-tropospheric water to localised deep convective systems (DC systems) is improved and applied to the EC-Earth climate model. Following Zelinka and Hartmann (2009), several fields related to moist processes and radiation from various satellites are composited with respect to the local maxima in rain rate to determine their spatio-temporal evolution with deep convection in the central Pacific Ocean. Major improvements to the earlier study are the isolation of DC systems in time so as to prevent multiple sampling of the same event, and a revised definition of the mean background state that allows for better characterisation of the DC-systeminduced anomalies.

The observed DC systems in this study propagate westward at $\sim 4 \mathrm{~ms}^{-1}$. Both the upper-tropospheric relative humidity and the outgoing longwave radiation are substantially perturbed over a broad horizontal extent and for periods $>30 \mathrm{~h}$. The cloud fraction anomaly is fairly constant with height but small maximum can be seen around $200 \mathrm{hPa}$. The cloud ice water content anomaly is mostly confined to pressures greater than $150 \mathrm{hPa}$ and reaches its maximum around $450 \mathrm{hPa}$, a few hours after the peak convection. Consistent with the large increase in upper-tropospheric cloud ice water content, albedo increases dramatically and persists about $30 \mathrm{~h}$ after peak convection.

Applying the compositing technique to EC-Earth allows an assessment of the model representation of DC systems.
\end{abstract}

The model captures the large-scale responses, most notably for outgoing longwave radiation, but there are a number of important differences. DC systems appear to propagate eastward in the model, suggesting a strong link to Kelvin waves instead of equatorial Rossby waves. The diurnal cycle in the model is more pronounced and appears to trigger new convection further to the west each time. Finally, the modelled ice water content anomaly peaks at pressures greater than $500 \mathrm{hPa}$ and in the upper troposphere between $250 \mathrm{hPa}$ and $500 \mathrm{hPa}$, there is less ice than the observations and it does not persist as long after peak convection. The modelled uppertropospheric cloud fraction anomaly, however, is of a comparable magnitude and exhibits a similar longevity as the observations.

\section{Introduction}

The impact of tropical deep convective (DC) systems on the upper troposphere and their overall effect on the global climate remain important areas of uncertainty. Deep convective activity plays a vital role in the vertical transport of moisture and aerosols into the tropical upper troposphere and greatly influences the temperature lapse rate, humidity profile, and the properties of clouds. Typically lasting $\sim 24 \mathrm{~h}$, DC systems exhibit horizontal coverage that can span up to thousands of square kilometres (Mapes and Houze, 1993) and 
provide a substantial source of precipitation in the tropics. Such a wide range of interaction leads to DC systems having a significant impact on the top-of-atmosphere (TOA) radiation balance via the generation of broad cirrus cloud shields.

The impact of deep convection on upper-tropospheric water has been studied, for example, by Mapes and Houze (1993), Webster et al. (1996), Chen et al. (1996), and Chen and Houze (1997) (including references therein) using infrared-derived cloud-top temperatures to identify tropical convective activity that reaches high in the atmosphere. Other studies regarding tropical deep convection have been more focused on investigating the interaction between DC systems and atmospheric variables, their effect on the incoming and outgoing radiation, as well as the transport of moisture into the upper troposphere (Tian et al., 2004; Soden, 2004, 2000). Both Lagrangian (Soden, 2004) and Eulerian (Zelinka and Hartmann, 2009) techniques have been used to investigate various aspects of DC systems, including the diurnal cycle (Eriksson et al., 2010).

The representation of tropical variability and its impact on the global atmosphere is an area of concern in climate projections from global climate models (GCMs). From a modelling perspective, problematic aspects often arise from the fact that convection acts on sub-grid scales and interacts with other atmospheric phenomena on a broad spatial and temporal scale (Bechtold et al., 2008; Gerard et al., 2009). In most current GCMs, such processes are handled implicitly by various parameterizations that can generate considerable modelling uncertainties. Consequently, GCMs are constantly being evaluated as a means of addressing and reducing uncertainties. Previous studies regarding the evaluation of GCMs using observations tend to employ straightforward seasonal, or annual, means; therefore, they have an inherent time resolution of months or longer. However, at such timescales it is difficult to assess the realism and identify errors of individual processes (Stephens et al., 2010). Evaluations of GCMs on shorter timescales are not as prevalent because of the limited availability of suitable observational datasets. While there are some observations with a temporal resolution on the order of hours, these are usually from ground-based stations (for example, the Atmospheric Radiation Measurement Program; Qian et al., 2012), or from very short research campaigns, with limited regional and/or temporal coverage, e.g. Aerosol Radiation and Cloud Processes affecting Arctic Climate (ARCPAC) and Airborne Tropical TRopopause EXperiment (ATTREX). Finally, GCMs are currently being evaluated with the aid of satellite simulators. Such evaluations are often concerned with clouds and cloud feedback processes (Bodas-Salcedo et al., 2008; Nam et al., 2012; Klein et al., 2013). Currently, satellite simulators in models do not offer the full range of sensors included in this study.

Studies of DC systems often rely on data acquired using geostationary sensors that operate in the infrared (IR) and/or visible part of the spectrum. Visible sensors are daytime only, and infrared radiation emission from the atmosphere and the surface is strongly absorbed by clouds (John et al., 2011; Liang et al., 2011). These sensors lack the ability to penetrate clouds and as such effectively report information only from the upper-most part of clouds. On the other hand, the high temporal resolution of geostationary data allows for the tracking of the horizontal movement of humidity patterns and the cirrus anvil generated by DC systems (Soden, 2004).

Polar orbiting satellites, in contrast, offer a much wider range of observation sensors, including measurements at microwave wavelengths having a better cloud penetration capability. A major drawback of observations from polar orbiting systems is the long time span between data acquisitions, a problem especially pronounced for low-latitude regions (Kirk-Davidoff et al., 2005). Thus, they do not allow for the horizontal tracking of the time evolution of individual convective systems or other atmospheric processes. However, mean responses of such systems can be derived, as shown by Field and Wood (2007) and Zelinka and Hartmann (2009, hereinafter ZH09). In ZH09, the anomalous response of moist processes to deep convection, against an established background state, was ascertained. The approach is based on an objective identification of reference points centred in space and time on maxima in satellite-derived rain rates (hereafter the term "DC system centre" refers only to the point of maximum rain rate (RR) and not the spatial centre of a DC system). Data from numerous satellite overpasses are then averaged, according to the distance in time and space to the identified DC system's centre point, and a two- or three-dimensional structure of different variables' response is obtained. An individual event will be sampled for only a few time bins and maybe for only part of the area considered, but when averaging over thousands of DC systems the mean patterns emerge. The data are averaged following the distance to fixed points. This compositing approach is advantageous as it retains properties of individual DC systems that would be lost in traditional spatial, or temporal, averaging and creates high temporal resolution results that are able to highlight aspects of atmospheric variability directly affected by DC systems (Field and Wood, 2007).

In this study, the ZH09 compositing technique is extended to diagnose convection-related and large-scale internal processes in the climate model, EC-Earth. This study is presented in two parts. This first part re-examines the identification of the convective centre points employed in the ZH09 study, presents data compilations not included in the ZH09 study (CloudSat-CALIPSO, Advance Microwave Sounding Unit B, Microwave Humidity Sounder, Cloud and Earth Radiant Energy System), and demonstrates the utility of the method for diagnosing EC-Earth's spatio-temporal evolution of deep convective processes over the central Pacific. In Part 2, the methodology is also applied to the ECHAM6 and CAM5 models participating in CMIP5 in a model intercomparison and over both land and oceanic regions. 


\section{Data}

\subsection{Observations}

\subsubsection{Surface precipitation}

Surface precipitation data, expressed as rain rate in $\mathrm{mmh}^{-1}$, are taken from the TRMM Multi-satellite Precipitation Analysis (TMPA) 3B42 version 6/6A dataset. A description of the dataset is given by Huffman et al. (2007). Briefly, the dataset is a combination of multiple precipitation estimates from several satellite sources, both microwave and infrared, as well as both geostationary and polar orbiting. Whenever possible, surface rain gauges are used to scale the data. These data, when combined, provide a continuous TMPA hourly RR every 3rd hour. Each of these ordinal hours consists of data collected within $\pm 90 \mathrm{~min}$ of each hour. The dataset is provided on a $0.25^{\circ}$ grid between $\pm 50^{\circ}$ latitude and with a time resolution of $3 \mathrm{~h}$. For the purpose of this study, the TMPA dataset is re-sampled to a $1^{\circ}$ grid, which is slightly lower than ECEarth's resolution (Sect. 2.2).

\subsubsection{Upper-tropospheric humidity}

Upper-tropospheric humidity (UTH) - defined here as the Jacobian-weighted, average relative humidity with respect to ice $\left(\% \mathrm{RH}_{\mathrm{i}}\right)$ from 500 to $200 \mathrm{hPa}$ - is derived from the Advance Microwave Sounding Unit B (AMSU-B) and Microwave Humidity Sounder (MHS) sensors on-board operational satellites run by the National Oceanic and Atmospheric Administration (NOAA) and the European Organisation for the Exploitation of Meteorological Satellites (EUMETSAT). In this study, UTH retrievals are obtained from AMSU-B on NOAA-16 and NOAA-17, and from MHS on NOAA-18 and MetopA (all satellite observation angles included). The AMSU-B/MHS sensors have a swath of about $2300 \mathrm{~km}$ with a footprint resolution, at nadir, of approximately $20 \times 16 \mathrm{~km}^{2}$. At the widest scan angels, the footprint is around $64 \times 52 \mathrm{~km}^{2}$. UTH is retrieved using the brightness temperature $\left(T_{\mathrm{b}}\right)$ at $183.31 \pm 1.00 \mathrm{GHz}$, as described in Buehler and John (2005). This is channel 18 of AMSU-B and channel 3 of MHS. The UTH is gridded to match EC-Earth's horizontal resolution of $\approx 0.7^{\circ}$.

An important aspect of this dataset is cloud penetration. The UTH retrieval assumes no scattering, but this normally sound assumption begins to break down in a DC system's clouds. Ice particles scatter emitted microwave radiation and lower the $T_{\mathrm{b}}$, thereby causing an overestimation of UTH. Although these measurements are much less sensitive to clouds than those from IR sensors (John et al., 2011), scattering is of particular significance in convective regions, and the degree of scattering is also dependent on satellite viewing angle. This is taken into account when screening the data, which involves the use of a cloud filter described in Buehler et al. (2007). The two-part filter uses a scan-angle-dependent $T_{\mathrm{b}}$ threshold, along with a filter considering the $T_{\mathrm{b}}$ difference to the neighbouring channels (19 or 20 for AMSU, and 4 or 5 for MHS).

Since data from several satellites are used, inter-satellite $T_{\mathrm{b}}$ biases become an issue. Such biases have been investigated by John et al. (2013) and found not to be so significant as to prevent the combination used in this study. For the remainder of this study, this UTH dataset will simply be referred to as AMSU.

\subsubsection{Cloud fraction and cloud ice water content}

The nadir-looking CloudSat cloud-profiling radar operates at $94 \mathrm{GHz}$ with a horizontal resolution of $\sim 2 \mathrm{~km}$ and a vertical resolution of $500 \mathrm{~m}$. Since June 2006, the instrument has provided height-resolved cloud properties, for example, ice water content and cloud fraction (Stephens et al., 2002). CloudAerosol Lidar with Orthogonal Polarization (CALIOP) is a space-borne lidar, on-board the Cloud-Aerosol Lidar and Infrared Pathfinder Satellite Observations (CALIPSO) satellite, that operates at wavelengths 532 and $1064 \mathrm{~nm}$ (Winker et al., 2007). This study uses the recently developed CloudSat and CALIPSO Ice Cloud Property Product (2C-ICE), which combines data from collocated CloudSat 2B-GEOPROF data and the measured attenuated backscattered coefficients from CALIPSO's $532 \mathrm{~nm}$ channel. A detailed technical description of the 2C-ICE dataset can be found on the CloudSat website: http://www.cloudsat.cira.colostate.edu/dataICDlist. php?go=list\&path=/2C-ICE.

The scattering properties at microwave and visible wavelengths lead to very different sensitivities of CloudSat and CALIPSO. Thin clouds consisting of smaller particles are only detected by CALIPSO, while parts of the atmosphere with a thicker cloud layer above are only probed by CloudSat. The vertical extension of the overlapping region between the two instruments differs depending on several cloud variables, such as liquid and ice water mass and the associated particle size distributions. For the tropical region, the point where CloudSat and CALIPSO show the same average cloud frequency is found consistently close to $200 \mathrm{hPa}$, and for lower (higher) altitudes the CloudSat frequency is, in rough terms, a factor two higher (lower) than CALIPSO (see Johnston et al., 2012, Fig. 4).

\subsubsection{Radiation}

TOA outgoing longwave radiation (OLR) flux observations are provided by the Cloud and Earth Radiant Energy System (CERES) sensors on-board the Aqua and Terra satellites. The hourly Single Satellite Footprint (SSF) cloud edition 3A hourly dataset is chosen for this study. This product combines CERES sensor data with information from the Moderate Resolution Imaging Spectroradiometer (MODIS) and the Visible and Infrared Scanner (VIRS) sensors. The level2 SSF dataset is taken from both satellites. Because each 
sensor has been radiometrically inter-calibrated, the two sensors can be considered as one. The data are then gridded to a regular grid $\left(\approx 0.7^{\circ}\right)$ following the resolution of EC-Earth (Sect. 2.2). An in-depth description of the CERES sensor is given by Wielicki et al. (1996) and a discussion of the measurement uncertainty, which is primarily due to calibration error and estimated to be about $\pm 5 \mathrm{~W} \mathrm{~m}^{-2}$, can be found in Loeb et al. (2009). Level-2 data do not contain albedo and therefore this is calculated using a formulation obtained from the CERES team.

\subsection{Climate model}

The global climate model used in this study is an emerging version of EC-Earth, version 3 (uncoupled). This version is based on the seasonal forecast version of the European Centre for Medium-Range Forecast (ECMWF) Integrated Forecast System (IFS) Cycle 36r4 (http://www.ecmwf.int/ research/ifsdocs). The model configuration has a horizontal grid resolution of $\sim 0.7^{\circ}$ (T255 spectral truncation) and 91 hybrid pressure-sigma coordinate levels with a model top at $0.1 \mathrm{hPa}$ and vertical grid spacing increasing with height ( $\sim 400 \mathrm{~m}$ in the upper troposphere). The model time step is set to $45 \mathrm{~min}$ and the output frequency is every 3rd hour. Prescribed boundary conditions, such as sea surface temperature, are taken from ERA-Interim monthly means.

Deep convection in EC-Earth is represented with a subgrid cumulus convection parameterization. The process is described using a bulk mass flux scheme with a pair of entraining and detraining (updraught and downdraught) plumes (Tiedtke, 1989; Bechtold et al., 2004, 2008). The model has prognostic variables for cloud liquid, cloud ice (pristine ice crystals), precipitating rain and precipitating snow (ice aggregates), in addition to a prognostic sub-grid cloud fraction. The stratiform cloud scheme is based on Tiedtke (1993) with modifications described in Forbes et al. (2011). All variables have sources and sinks from the stratiform microphysical processes and detrainment from the convection parameterization is also a source of cloud liquid, cloud ice and cloud fraction. The prognostic variables therefore represent both stratiform cloud as well as anvil cloud associated with deep convection. In addition to the prognostic rain and snow precipitation from the stratiform scheme, there is also a diagnostic convective core precipitation from the convection scheme. A sub-grid precipitation fraction is diagnosed within the model but this was not available as output for this study, so this hydrometeor fraction is missing when comparing to the "cloud fraction" derived from the 2C-ICE product. However, for the ice water content comparison, a snow water content derived from the convective core snow flux is added to the stratiform cloud ice and snow water contents in order to be more representative of the total hydrometeor content observed in the 2C-ICE dataset. Note that while both stratiform cloud ice and precipitating snow are considered in the radiation calculations, the convective core snow is not.
In this study a subset of variables is compared with the observed retrievals. They are RR, UTH, cloud fraction, ice water content, OLR, and albedo. The surface precipitation used in this study is the sum of the stratiform and convective precipitation. UTH is taken as the grid-box mean relative humidity with respect to ice. Albedo, $\alpha$, is calculated as

$\alpha=1-\frac{\mathrm{SW}_{\text {net }}}{\mathrm{SW}_{\text {in }}}$,

where $\mathrm{SW}_{\text {net }}$ is the model's TOA net (incoming minus reflected) short-wave radiation, and $\mathrm{SW}_{\text {in }}$ is the product of the solar constant and the cosine of the solar zenith angle. Albedo was derived for zenith angles between $0^{\circ}$ and $85^{\circ}$. Inclusion of higher angles was found to give less stable results.

The radiation and precipitation variables are accumulated fields over the three hourly output frequency time, and they are converted to mean values and rates, respectively, by division with the output frequency. Non-accumulated variables are interpolated to the centre of the time steps in order to match the accumulated variables.

\section{Method}

In this study, the core idea of ZH09 is maintained, but the methodology has been modified in some aspects. The motivation for changes arises from the fact that the selection of a DC system in ZH09 ignored the potential for crosscontamination of the time bins, which may have caused an unintentional smoothing of the results, and that their definition of the background state included the anomaly itself. Following a recommendation in $\mathrm{ZH09}$, the spatio-temporal window is increased. This section summarises the ZH09 method and the adjustments made in this study.

\subsection{Zelinka and Hartmann (2009)}

ZH09 used data from polar orbiting satellites to assess atmospheric effects of DC systems during the period 2003 to 2005 for a part of the equatorial Pacific Ocean $\left(5^{\circ}\right.$ to $15^{\circ} \mathrm{N}$ and $120^{\circ}$ to $160^{\circ} \mathrm{E}$ ). Identification of a DC system's centre was done by using RR from the TMPA dataset (same version as used here). This multiple-satellite dataset allows for the identification of DC system centres with a spatial and temporal resolution of $0.25^{\circ}$ and $3 \mathrm{~h}$, respectively, though ZH09 analysed TMPA after first averaging the data to $1^{\circ}$ resolution.

Candidates for DC systems were selected from RRs exceeding the 90th percentile $\left(>1.6 \mathrm{mmh}^{-1}\right)$, which contributed about $57 \%$ of the total $\mathrm{RR}>0$ for that region and period 2003 to 2005. Adjacent grid spaces containing RRs exceeding the threshold were averaged into one distinct realisation. This method assumes that the selected RR values, now taken as the centre point in both space and time for peak convection, coincides closely with the strongest convection. 
A typical DC system can cover thousands of $\mathrm{km}^{2}$, and the resulting effects on the atmosphere extend over even larger areas. Accordingly, ZH09 considered a geographical area of size $11^{\circ} \times 11^{\circ}$ around the "centre" of each DC system over a time range of $\pm 24 \mathrm{~h}$ divided into time bins separated by $3 \mathrm{~h}$. They calculated the mean of all data from satellite passes falling into each spatio-temporal bin over the $3 \mathrm{yr}$ period, resulting in a composite depicting the mean evolution of the DC systems observed. This averaging compensates for the fact that a specific DC system is observed by a Sun-synchronous sensor, at best, twice every $24 \mathrm{~h}$ separated by $12 \mathrm{~h}$. Figure 1 exemplifies the outcome of this averaging process. The OLR data in the panels are divided into the different satellites, Aqua (a) and Terra (b), and then by RR, strongest $50 \%$ (c) and weakest $50 \%$ (d), in order to better illustrate some aspects discussed in Sect. 4.2. In the remaining two panels, the data are combined into a single composite. Equatorial passage times for Aqua and Terra are 01:30 LST/13:30 LST (local solar time) and 10:30/22:30 LST, respectively.

\subsection{Modifications of the methodology}

The selected geographical area for the study is bounded by \pm 15 in latitude and 140 to $260^{\circ} \mathrm{E}$ in longitude. A sub-area around New Guinea is masked out in order to avoid landbased convection that has a different diurnal cycle. The region described is used for selecting the centre points of DC systems, but the data that are compiled can extend outside the given boundaries. The time period used is 2007 to 2008 . The relative time window is set to $\pm 48 \mathrm{~h}$, and the spatial window of the composite mean is set to $21^{\circ} \times 21^{\circ}$. When displaying the plots of the spatial mean and the anomaly, the window size is often reduced in order to better focus on the DC system's signature. The orientation of each composite and anomaly plot is north to south and west to east such that the latitude and longitude values are set to $-10^{\circ}$ to $10^{\circ}$ from the DC centre values.

There are cases when two or more RR values above the threshold occur in adjacent space or time bins and are highly likely part of the same convective system. Selecting such DC systems would result in overlap in the time dimension and introduce a smoothing effect. This is solved by sorting the DC systems in order of decreasing RR. The position of the highest RR is classified as a DC system centre, and all other RRs within $12^{\circ} \times 12^{\circ}$ and $\pm 18 \mathrm{~h}$ are removed from the processing chain. The highest remaining RR becomes a new DC system centre and so forth.

Using the satellite RR retrievals, a centre point for each of the most intense DC systems inside the region is determined, in both time, $t_{0}$, and space, $\left(x_{0}, y_{0}\right)$. This is followed by a processing of data from a range of satellite sensors. Each satellite observation, at $\left(x_{\mathrm{s}}, y_{\mathrm{s}}, t_{\mathrm{s}}\right)$, contributes to the final average for the relative time $(\Delta t)$, latitude $(\Delta y)$ and longitude $(\Delta x)$ bin encompassing $(\Delta x, \Delta y, \Delta t)=\left(x_{\mathrm{s}}-x_{0}, y_{\mathrm{s}}-y_{0}, t_{\mathrm{s}}-t_{0}\right)$.
That is, the satellite data are averaged according to the time and geographic distance to the DC system centre points. The temporal bins are $3 \mathrm{~h}$ apart, with $-48 \mathrm{~h}$ and $48 \mathrm{~h}$ as the first and last bins respectively. With the exception of the TMPA dataset, which is re-sampled to $1^{\circ}$, the latitude and longitude bins are $\approx 0.7^{\circ}$ wide and have a total coverage of $\approx 21^{\circ}$ in each dimension.

\subsection{Expanding the study}

A largely different set of sensors is considered in this study that both complements the results already reported in ZH09 and also simplifies the comparison with models. Cloud interference is not only an inherent issue for satellite sounding but also complicates strongly the comparison to model data. For this reason, "all sky" OLR has been chosen instead of the "clear sky" OLR. Also, an additional extension to this study is the examination of a DC system's effect on the TOA net short-wave radiation through its effect on albedo. In addition, UTH is taken from microwave observations rather than from Atmospheric Infrared Sounder (AIRS). This is motivated by the need to reduce cloud interference in the data because the AIRS retrieval rejects scenes with a cloud fraction $>70 \%$ (John et al., 2011; Liang et al., 2011). Rather than using passive cloud retrievals, as in ZH09, this study employs the active sensors on-board CloudSat and CALIPSO to derive cloud fraction and cloud ice water content.

The modified ZH09 approach is applied to evaluate the evolution of deep convection in a GCM. DC systems inside the model are also identified using RR. We ensure that only convection generated by the model's deep convection scheme are chosen by using a diagnostic flag that identifies when this particular scheme is active. The model and TMPA are processed in their native grids using different thresholds for the DC systems's RR because of the difference in their peak RR intensities. The maximum RR in the model is $\approx 10 \mathrm{mmh}^{-1}$, while in the TMPA dataset it is $\approx 70 \mathrm{~mm} \mathrm{~h}^{-1}$. Taking the 90 th percentile of each RR source results in a much larger TMPA sample size than for the model. The TMPA sample would in this case introduce a bias towards the weaker cases. This is solved by taking the strongest 11000 cases in each dataset. Matching the sample size removes the need to consider the different RR intensities and removes sampling biases.

\section{Results and discussion}

In comparison to earlier works (ZH09; Horváth and Soden, 2008; Soden, 2004), this study takes a step forward by extending both the temporal and horizontal coverage. Perhaps the most important aspect is the extension backward in time to obtain a more robust estimate of the background state. On the other hand, there exist studies following the detrained air over five days using trajectories estimated by wind data taken from models (Luo and Rossow, 2004; Wright et al., 2009), 


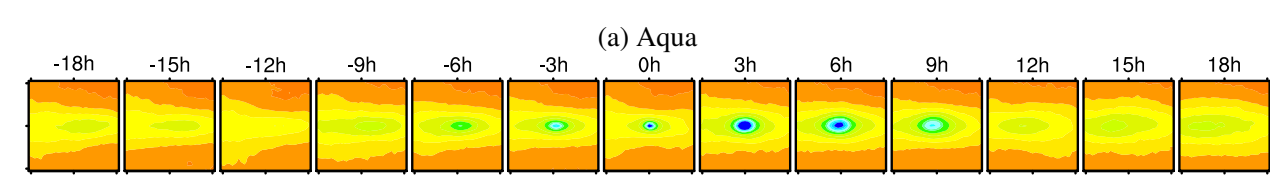

(b) Terra

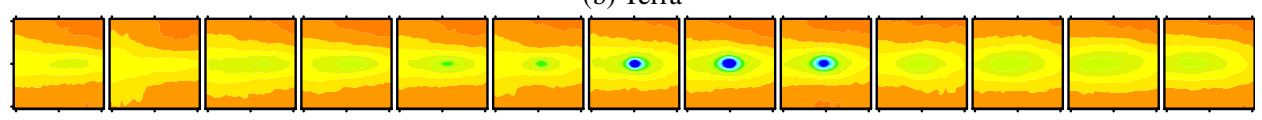

(c) Combined strongest RR

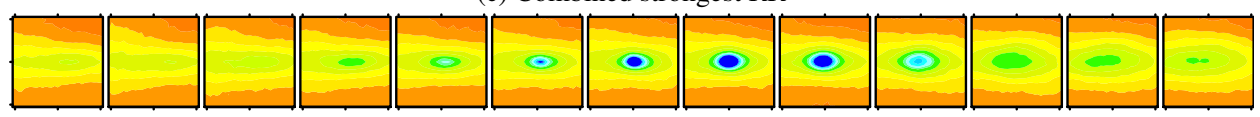

(d) Combined weakest RR

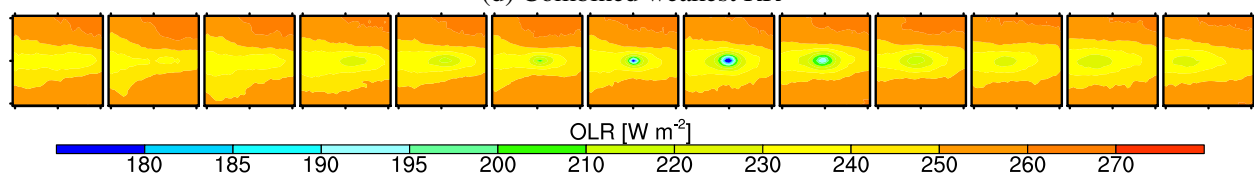

Fig. 1. OLR composite means, averaged as described in Sect. 3.2, from the CERES sensors on-board the Sun-synchronous satellites Terra and Aqua. Friezes (a) and (b) show OLR for all DC systems for each sensor separately. In panels (c) and (d) the two sensors are combined, but the DC systems have been divided: frieze (c) includes the top 50\% (21.6 to $\left.70.0 \mathrm{mmh}^{-1}\right)$ of the 11000 strongest cases, and frieze (d) shows the remainder. The spatial extent of each plot is $12^{\circ} \times 12^{\circ}$.

but those analyses are restricted to the period after peak convection. The results of this study are presented and discussed by first examining the probability density function of the total RR and the diurnal distribution of the DC systems (Fig. 2). This is followed by a look at the composite mean (Fig. 3) and then the anomaly (Figs. 4, 5, and 6). In many of the results, a propagation of the mean DC system anomaly is discernible after peak convection. This section concludes with a look at the time-longitude behaviour of the DC systems and a discussion of their propagation westward, or eastward, with equatorially trapped waves. In each subsequent section, the observations are presented followed by the model.

\subsection{Rain rate statistics}

Figure 2 (top) shows the probability density functions (PDFs) of the RR data taken in their native grid resolutions (TMPA $0.25^{\circ}$ and EC-Earth $0.7^{\circ}$ ) plus the TMPA data re-sampled to $1^{\circ}$ and $2^{\circ}$. The RR in both the model and TMPA (native and re-sampled grid) show a monotonic decline in frequency going towards the higher RR. While TMPA (native) reports $\mathrm{RR}$ up to $\approx 70 \mathrm{mmh}^{-1}$, the highest precipitation in EC-Earth is $\approx 10 \mathrm{mmh}^{-1}$. This difference is partly explained by the spatial resolutions for the two datasets, but a re-sampling of TMPA to $1^{\circ}$ resolution (green curve), or $2^{\circ}$ resolution (black curve), shows that the model strongly underestimates the frequency of intense RR. Another possible contributor to the difference is the fact that the model data are a temporal average over a three-hour period, whereas the observations are more likely to be made up of only a few overpasses during the three-hour period, which is more representative of instantaneous values. However, it is very likely that this signal is a real difference, with high rain rates underestimated in the model. Moreover the frequency of light rain, typically $<1.0 \mathrm{mmh}^{-1}$, is overestimated in the model. Similar findings, highlighting the poor representation of the PDF of surface precipitation in models, were reported by Stephens et al. (2010). Despite the underestimate of high RR in the model, the average precipitation is in fact higher in EC-Earth $\left(\approx 0.20 \mathrm{~mm} \mathrm{~h}^{-1}\right)$ than in TMPA $\left(\approx 0.14 \mathrm{mmh}^{-1}\right)$.

The PDF of TMPA DC systems (lower left plot) over $24 \mathrm{~h}$ shows a predominance from late evening, $\sim 21 \mathrm{~h}$, to midmorning the next day, $\sim 9 \mathrm{~h}$. From the early morning maximum PDF of $\sim 2 \%$, the frequency of DC systems decreases during the day to a clear minimum around $18 \mathrm{~h}$. Mapes and Houze (1993), using infrared satellites to classify "cloud clusters", found a shift in the peak times of DC systems based on their horizontal coverage (intensity). We do not see this shift explicitly in the figure, but its presence is implied by the aliasing seen in Fig. 1. Alcala and Dessler (2002, Fig. 6), using data from the Tropical Rainfall Measuring Mission (TRMM) satellite, found some variation in the peak times for DC systems over ocean, albeit for one season. The results of this study compare better with Nesbitt and Zipser (2003), who, also using data from the TRMM satellite and for a three-year period, found a peak occurrence of DC systems in the early morning over ocean. An examination of the model's DC systems (lower right plot) reveals a similar peak RR occurrence after midnight. The duration of this maximum in the PDF in the model, however, is considerably shorter. 

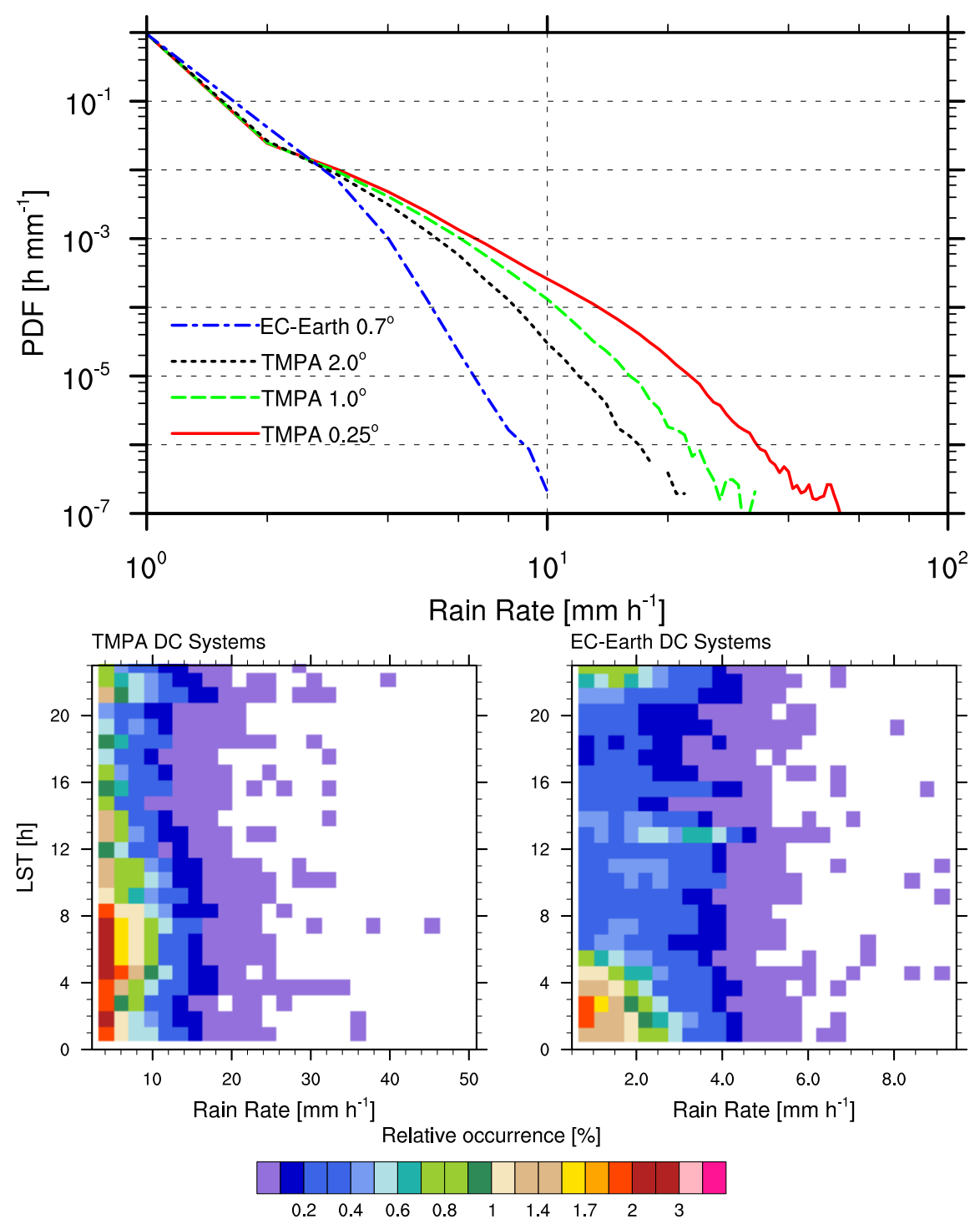

Fig. 2. Probability density functions (PDFs) (top) of the total precipitation over the central Pacific region. The curves are normalised by dividing the total number of cases in each bin by the bin size and the total number of valid data points. TMPA in its native resolution (red curve), re-sampled to $1^{\circ}$ (green curve) and $2^{\circ}$ (black curve), and the model (blue curve). Bivariate PDF of TMPA's DC systems (bottom left) per LST, while the bottom right panel is the same but for EC-Earth. Note the different $x$ axis ranges.

\subsection{Averaging considerations}

With the exception of the TMPA dataset, all satellites used in the study are in Sun-synchronous orbits. A sensor in such an orbit performs measurements around the Equator at two fixed local solar times that are twelve hours apart. Consequently, the spatio-temporal occurrence of peak convection becomes significant because the peak occurs at night and occupies a small part of the diurnal cycle. This means that some time bins will be preferentially influenced by DC systems. Thus, an aliasing effect is created between the sampling of the Sun-synchronous satellites and the diurnal cycle of convection. The overpass times of the Sun-synchronous satel- lites are, therefore, reflected in the results. This aliasing is apparent in Fig. 1, where averages from two different sensors are compared. For CERES Aqua, discontinuities in the time series are seen at $-12 \mathrm{~h}, 0 \mathrm{~h}$, and $12 \mathrm{~h}$, while for CERES Terra this pattern is shifted to $-15 \mathrm{~h},-3 \mathrm{~h}$, and $9 \mathrm{~h}$. This is consistent with the fact that Terra has an ascending node that is $3 \mathrm{~h}$ earlier.

Aliasing effects are much less pronounced in the results of ZH09, despite the fact that they only used datasets from single Sun-synchronous satellites (TMPA excluded). As seen in Fig. 3, at the geographical centre point, a high RR is maintained between at least $-3 \mathrm{~h}$ and $3 \mathrm{~h}$. In ZH09 the RR data were analysed for each time bin in isolation (Sect. 3), and it is 
likely that many persistent, intense convective systems were each inserted as separate DC systems, causing the same ones to be sampled multiple times and smoothing out aliasing. The area selected by ZH09 includes convection over land, that has another diurnal cycle, which can also affect the results.

\subsection{Spatial patterns}

The spatio-temporal evolution of RR (TMPA re-sampled to 1), UTH, cloud ice water content, cloud fraction, albedo, and OLR are shown in Figs. 3 and 4. Figure 4 shows the anomalies isolated from the background state for a subset of the variables that are least noisy. The background state is taken as the zonal mean over the first twelve hours of the composite period. More precisely, for each latitude, the mean state is computed as the average over all longitude bins of the $-48 \mathrm{~h}$ to $-39 \mathrm{~h}$ time bins. Because $\mathrm{ZH} 09$ computed the background state as the average over all horizontal bins for the entire composite period, it included the anomaly and was therefore perturbed from a true background state. One must bear in mind that the horizontal extent of the anomaly is the mean of the 11000 cases and does not represent a single DC system. In this section the words "mean" and "anomaly" will refer to Figs. 3 and 4 respectively.

\subsubsection{Observations}

High RR means are strongly focused around the DC systems centre point, and significant deviations from the background state are confined to $\pm 6 \mathrm{~h}, \pm 2^{\circ}$ in latitude and $\pm 3^{\circ}$ in longitude. The region of elevated mean RRs shows a shift, i.e. "propagates", westward at $\approx 4 \mathrm{~m} \mathrm{~s}^{-1}$. This region of higher RR is better illustrated in the anomaly plot (Fig. 4) where a somewhat symmetrical pattern, in time, of change in RR is evident and centred around the time of peak convection. ZH09 also identified a mean westward movement of about $\approx 6 \mathrm{~m} \mathrm{~s}^{-1}$, which is consistent with the movement of synoptic disturbances observed in the ITCZ (Reed and Recker, 1971). An extended discussion of this movement is given in Sect. 4.4.3.

A general feature common to all the observations is the presence of an eastward-sloping gradient in the results. The geography of the region chosen for this study sets the Tropical Warm Pool, a region known for having the highest occurrence of tropical convection, in the western-most portion of the box. This gradient of higher values to the west is therefore the result of the fact that a higher activity of deep convection is found there. One can clearly see this gradient in Figs. 1 and 3 and later on in Fig. 4.

The AMSU data show an area of increased mean UTH at about $0 \mathrm{~h}$. The horizontal extent of the core of the DC system continues to increase radially after peak convection until about $6 \mathrm{~h}$. At this point in time, the feature covers $\approx 3 \times 10^{4} \mathrm{~km}^{2}$. Afterwards, the core begins to decrease in humidity and expansion of the UTH is seen only radially un- til the anomaly extends beyond the grid box after $15 \mathrm{~h}$. Therefore, the true extent of the anomaly and its magnitude remain undetermined. Locally, UTH can be elevated to about 40 percentage points above a background state of $\sim 45 \%$.

The cloud ice water content and cloud fraction results are noisy. Although CloudSat and CALIPSO provide a high number of observations, the atmospheric volume sampled is roughly three orders of magnitude smaller than for passive instruments. This is due largely to the sensors' respective swaths, which are $\sim 2 \mathrm{~km}$ for CloudSat and $2300 \mathrm{~km}$ for AMSU-B. This gives a much smaller sampling coverage for instruments with narrow swaths. In addition, the time series are also disturbed by aliasing. The cloud fraction and cloud ice content are lower at $-12 \mathrm{~h}, 0 \mathrm{~h}$, and $12 \mathrm{~h}$ than for the adjacent time bins. For these reasons cloud ice water content and cloud fraction variables are not included in Fig. 4. While these variables are problematic, they still offer an opportunity to get an idea of the 3-D atmospheric response, which will be taken up in Sect. 4.4.1.

A peak in the albedo $(\approx 0.43)$ occurs sometime around $3 \mathrm{~h}$. There is a drop in mean OLR caused by the DC systems' clouds that culminates around $3 \mathrm{~h}$ at $\approx 80 \mathrm{Wm}^{2}$. Moreover, there is a distinct broadening of the spatial extent of the OLR anomaly after peak convection, and this is also seen in the CF. The spreading of the CF and OLR is not reflected in the albedo, which suggests a reduction in the cloud optical thickness radially from the centre of the DC systems' core, but with a stronger gradient latitudinally.

\subsubsection{EC-Earth}

This section discusses the use of the ZH09 method to evaluate DC systems' evolution in the GCM EC-Earth. The model's performance is discussed and its representation of DC systems is highlighted within the capability of this compositing method. We also underscore the value of the technique for model evaluation as complementary to more traditional comparisons of temporal averages, since it provides a more targeted analysis of the deep convective processes in the model. Part 2 of the study will go a step further and extend the comparison to include two other prominent models.

The compilation of model data is relatively straightforward, as the data are continuous in all dimensions, with the exception of albedo. Consequently, no aliasing effect is seen in the other variables. The RR shows a similar symmetry around $0 \mathrm{~h}$ to the observations but indicates a mean eastward movement of DC system. This implies a predominance of Kelvin waves over easterly waves, in contrast to the observations (Wheeler and Kiladis, 1999; Lin et al., 2008; Hendon and Wheeler, 2008). More on this in Sect. 4.4.3.

There is a mean background cloud ice content of $\sim 2$ to $4 \mathrm{mg} \mathrm{m}^{-3}$, compared to the observations, which despite being noisy, has mean values up to $\sim 12 \mathrm{mg} \mathrm{m}^{-3}$. In the centre of the DC system composite, the cloud ice water content exceeds, locally, $20 \mathrm{mg} \mathrm{m}^{-3}$ at its maximum at 

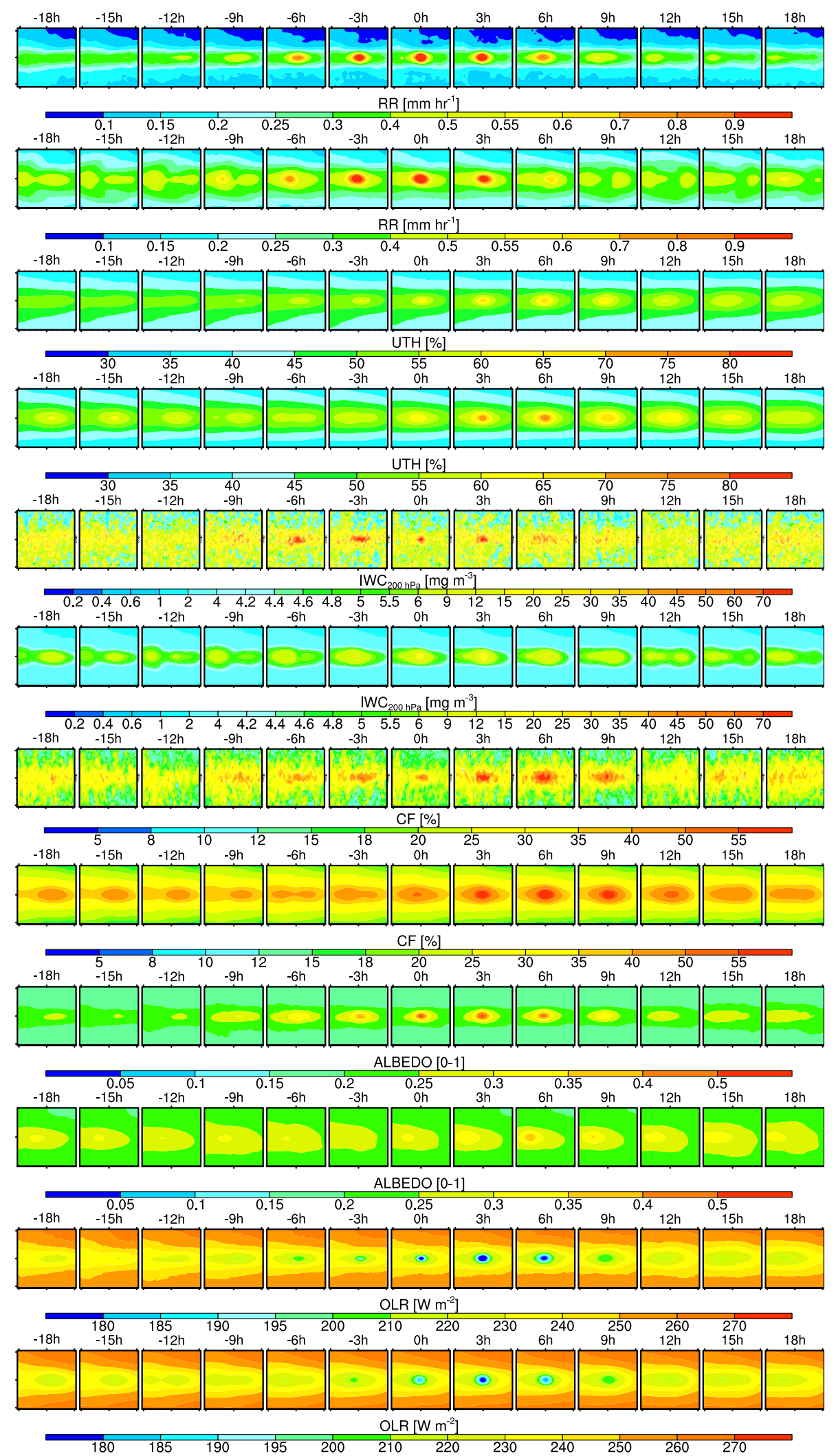

Fig. 3. Composite mean friezes for RR, UTH, IWC, CF, albedo, and OLR. CF and IWC are given for $200 \mathrm{hPa}$. The time bins between $\pm 18 \mathrm{~h}$ are shown and the spatial size of each plot is a $12^{\circ} \times 12^{\circ}$ box. For each frieze pair, observations are on top and the model is given directly below. 
$3 \mathrm{~h}$ with an horizontal coverage of about $4^{\circ} \times 4^{\circ}$. The model shows significant decrease of ice by $9 \mathrm{~h}$. The peak in the mean $200 \mathrm{hPa}$ cloud fraction occurs around $6 \mathrm{~h}$.

Several factors complicate the interpretation of the albedo response in the model. The derivation of albedo is limited to daytime and is greatly affected by the solar zenith angle as well as the representation of the DC systems' diurnal cycle in the model. There is a nighttime peak, with a long duration of several hours, in the cycle of the observations (Fig. 2, lower right plot). The model misses the duration of early morning peak, and even the PDF during the daylight hours is lower than what is observed. With so many DC systems occurring at night, not enough time bins will have daylight. This creates an especially strong dependence on the accuracy of the model's diurnal cycle representation. Furthermore, the EC-Earth configuration chosen for this study is close to that submitted to the fifth phase of the Coupled Model Intercomparison Project. In this configuration the radiation scheme is called every $3 \mathrm{~h}$, rather than $45 \mathrm{~min}$ (the model time step used for this study), and the radiation calculations are done on a coarser horizontal grid before being interpolated to $0.7^{\circ}$. Thus, the diurnal cycle generated will be based on fewer temporal and horizontal grid points as well as involving interpolation. This treatment is a computational trade-off that could contribute to the differences with respect to CERES (Fig. 3). One way to separate the effects of the model's representation of the diurnal cycle of DC systems and their radiative effects is to restrict the solar zenith angle. This limitation produces much more stable results that match more closely the observations. Therefore, what is seen in Figs. 3 and 4 is model albedo restricted to cases where the solar zenith angles are $\leq 45^{\circ}$.

While many of the oscillatory effects have been removed by the solar angle restriction, the model albedo still misses much of the extent and timing of the elevated reflection caused by the deep convective clouds. A maximum albedo of $\sim 0.35$, somewhere between 3 and $6 \mathrm{~h}$, is significantly less than the $\sim 0.5$ observed by CERES. Also, some time bins, $-9 \mathrm{~h}$ and $-6 \mathrm{~h}$, for example, show a slightly higher albedo that is latitudinally broader than observed. This suggests that there are too many clouds being produced and/or that the optical depth of clouds, away from the DC systems, is too high. This results in a higher background albedo in the model than seen in the observations. Consequently, the anomaly seen in Fig. 4 is of much smaller spatial extent and weaker in intensity than what is observed by CERES.

The model's minimum in OLR occurs from around $3 \mathrm{~h}$ to $6 \mathrm{~h}$, which is in good agreement with CERES, although the drop in the core of the DC system is seen approximately $3 \mathrm{~h}$ earlier in the observations. The composite shows that both the model and observations report a mean DC system whose effect on the OLR is of similar horizontal size and magnitude.

\subsection{Spatially averaged anomaly time series}

The time evolution of geographically averaged anomalies is shown in Figs. 5 and 6 . The domain size for this additional averaging is set to $\pm 6.5^{\circ}$ latitude and $\pm 10.5^{\circ}$ longitude (Fig. 5) and $\pm 3^{\circ}$ latitude and $\pm 10.5^{\circ}$ longitude (Fig. 6) of the centre point. This is done in order to avoid including areas outside the impact region of the convection and to better focus on the core of DC system. The background state is taken as the mean of the first four time bins, which is to say from $-48 \mathrm{~h}$ to $-39 \mathrm{~h}$. The evolution of domain average albedo, OLR, UTH, and RR anomalies over $96 \mathrm{~h}$ is shown in Fig. 5, while vertical profiles of spatial-mean cloud ice water content and cloud fraction are shown in Fig. 6. The 2CICE dataset is excluded from the results displayed in Fig. 5 because of relatively poor sampling, as seen in the cloud ice water content and cloud fraction panels of Fig. 3. Rather than exhibiting relatively smooth and monotonic growth and decay, the spatial average anomalies, with the exception of the TMPA RR, tend to be rather oscillatory in both the observations and model, with several local minima and maxima notable in the UTH, OLR, and albedo curves. These features, which in many cases are likely sampling artefacts, complicate attempts to objectively quantify the anomaly's exact magnitude, onset, and duration.

\subsubsection{Observations}

Figure 5 shows that the mean RR anomaly, at its most intense, rises $\approx 0.09 \mathrm{mmh}^{-1}$ above the background state. There is a monotonic increase of the RR starting from about $-15 \mathrm{~h}$ to peak convection and decreasing in a similar manner up to $15 \mathrm{~h}$. The OLR and UTH anomalies' changes are negatively correlated; however, the UTH seems to peak a bit later than the OLR minimum at $\approx 18 \mathrm{~h}$, at about 3 percentage points above the background state. Similar to the OLR, the UTH anomaly lasts for a longer time after peak convection. However, while the OLR tends towards complete relaxation close to $48 \mathrm{~h}$, the UTH seems to achieve this sometime thereafter. The OLR anomaly reaches its minimum at about $3 \mathrm{~h}$ with a value of $\approx-8 \mathrm{Wm}^{2}$. Finding a maximum albedo is hampered by the aliasing artefacts discussed earlier, but this variable shows a response to the changes in clouds prior to and post peak convection.

Figure 6 shows the temporal evolution of the 2C-ICE spatially averaged and smoothed profiles of cloud fraction anomaly (left column) and cloud ice water content anomaly (right column) between 500 and $100 \mathrm{hPa}$. The maximum of the cloud fraction occurs about $5 \mathrm{~h}$ after peak convection, but, for ice water content, this occurs sometime around peak convection. Cloud fraction anomaly response is greatest ( $\sim 7$ percentage points) at pressures $\leq 300 \mathrm{hPa}$, but there is also a clear response at pressures $\geq 300 \mathrm{hPa}$ reflecting the core of the convective event. In contrast, the largest cloud 


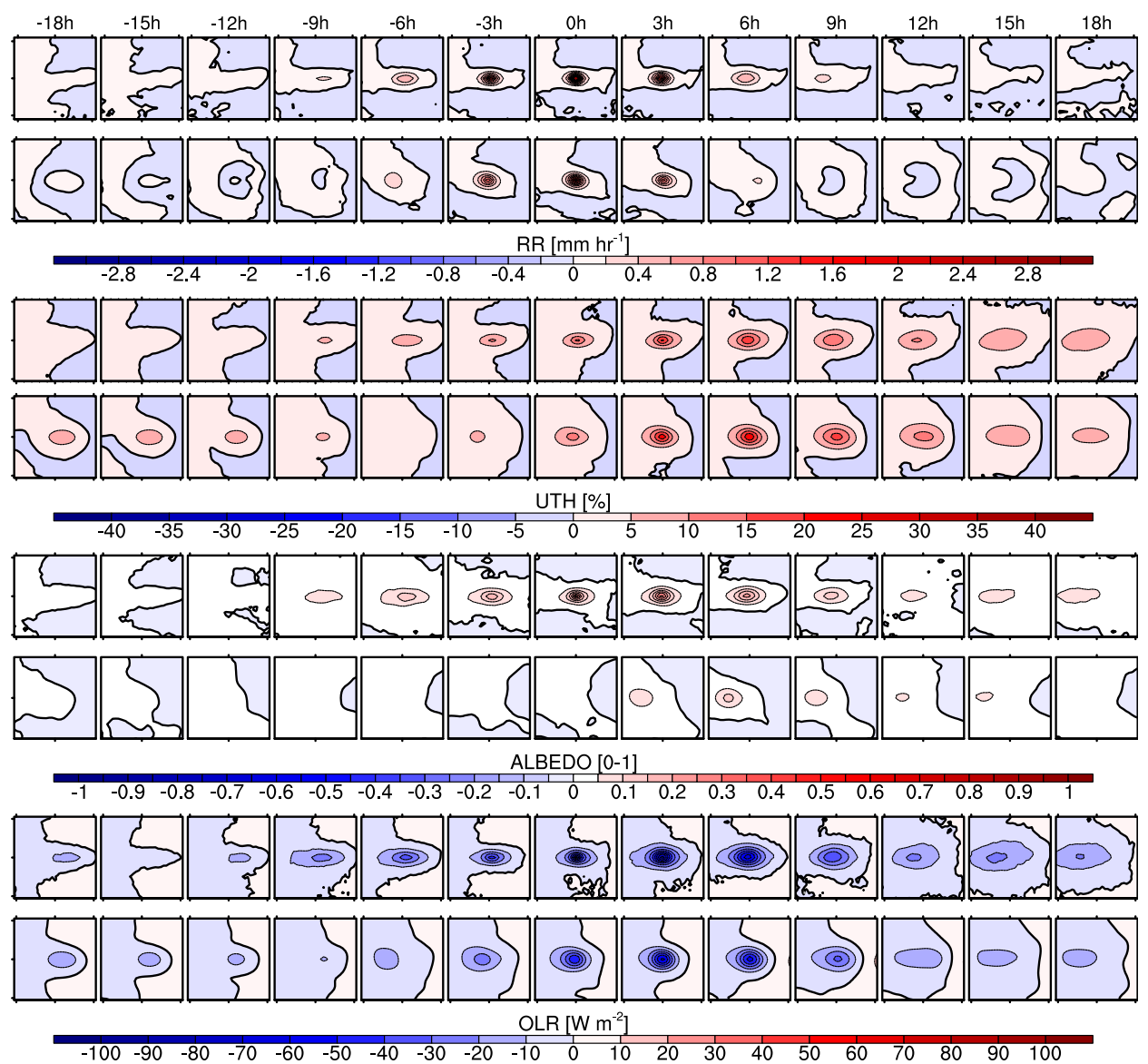

Fig. 4. Anomaly friezes for RR, UTH, albedo, and OLR. All other aspects of the figure are as Fig. 3. The zero line is indicated by a bold line.

ice water content anomaly $\left(\sim 20 \mathrm{mg} \mathrm{m}^{-3}\right)$ occur at pressures $\geq 300 \mathrm{hPa}$, but significant up to at least $150 \mathrm{hPa}$.

\subsubsection{EC-Earth}

The model OLR follows, in general, the observations and has, roughly, similar timing of its minimum after peak convection (Fig. 5) in the observations. However, the model's response of about $\sim-5 \mathrm{~W} \mathrm{~m}^{2}$ at its minimum is either equal to or warmer than the observations after peak convection. With regards to albedo, the restriction placed on the solar zenith angle, while producing a better mean composite match with CERES, results in a reduced sample size. Nevertheless, the model albedo anomaly follows the observations, albeit being systematically lower than that measured by CERES.

The maximum value of the RR anomaly remains close to the observations but shows a fast rise to peak convection and a quicker relaxation than TMPA. The initiation of new convection according to the diurnal cycle, $-24 \mathrm{~h}$ and $24 \mathrm{~h}$, is stronger in the model than the observations. The model RR anomaly peaks at about $0.06 \mathrm{~mm} \mathrm{~h}^{-1}$ but, unlike the observations, falls off sharply after peak convection.
Figure 6 clearly illustrates that the model's cloud fraction anomaly is greatest at pressures $\leq 300 \mathrm{hPa}$, reaching a maximum between $0 \mathrm{~h}$ and $6 \mathrm{~h}$. The response of clouds in between $250 \mathrm{hPa}$ and $150 \mathrm{hPa}$ is in good agreement with the 2C-ICE observations, with both maxima very close to $200 \mathrm{hPa}$. However, there is a clear underestimation of clouds in the model at pressures greater than $300 \mathrm{hPa}$ in the model. A contributing factor for this is the different definition of clouds in the observational data and the model output. The 2C-ICE cloud fraction includes precipitating hydrometeors, whereas the model cloud fraction does not. Precipitation fraction was not available from the model for this study. Furthermore, a separation of precipitating and non-precipitating clouds could be done following, for example, Chen et al. (2011), but this goes beyond the scope of this study.

Although the cloud fraction diagnostic from the model does not contain precipitating snow, the ice water content used here does include cloud ice, precipitating stratiform snow (e.g. from convective anvils) and precipitating convective snow produced in the convective updraught. The latter is a diagnostic variable and is converted offline from a 

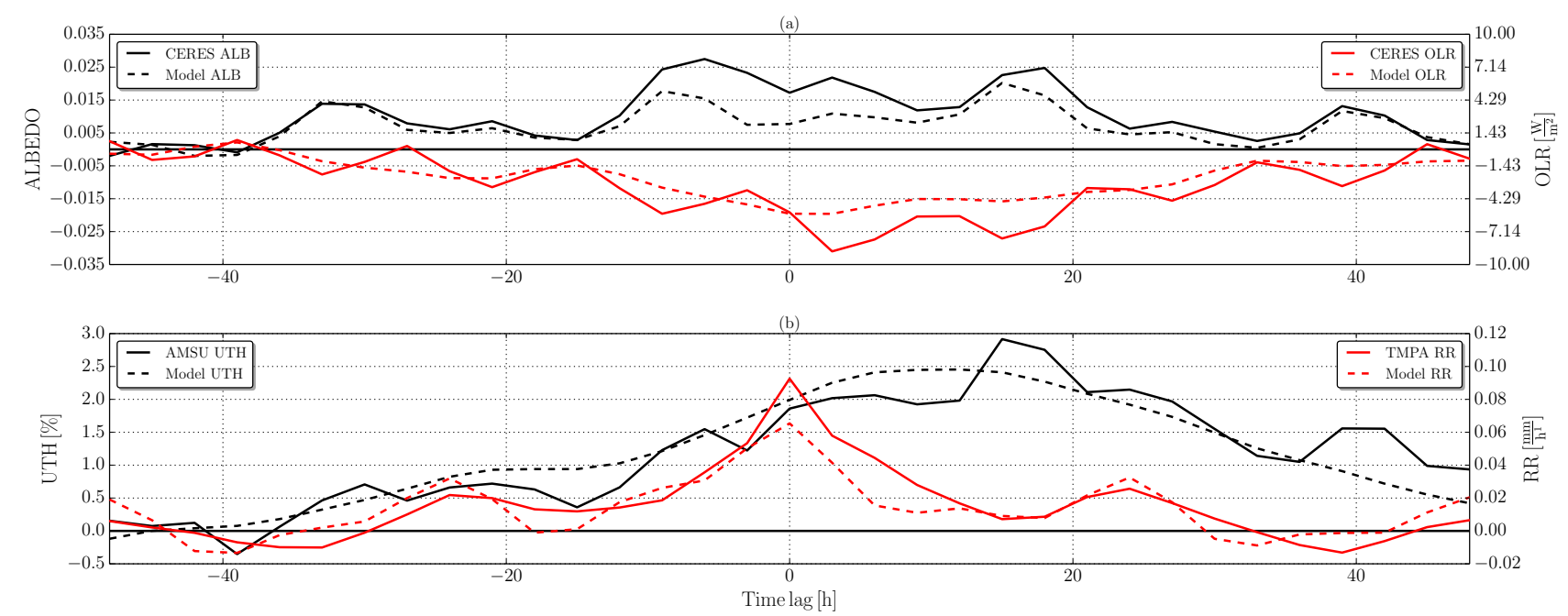

Fig. 5. Observed (solid) and modelled (dashed) anomalies in albedo, OLR, UTH, and RR, averaged over a region spanning $\pm 6.5^{\circ}$ latitude and $\pm 10.5^{\circ}$ longitude of the composite centre point. The background state (i.e. the zero level) is taken as the average of $-48 \mathrm{~h}$ to $-39 \mathrm{~h}$.

precipitation flux to ice water content using an assumed constant fall speed. The signature of the DC system ice water content anomaly in the model (Fig. 6) extends into the upper troposphere to similar levels as the observations and, at a ratio of about one to three, injects less ice at the higher altitudes than seen in the 2C-ICE data. Ice reaching levels from 200 to $150 \mathrm{hPa}$ persists for $\sim 20 \mathrm{~h}$, which is shorter than the observations. The timing of the cloud ice water content maximum is situated around $0 \mathrm{~h}$, slightly earlier than in the observations, but there is also a distinct diurnal cycle with secondary maxima at $\pm 24 \mathrm{~h}$ not seen in the observed ice water content anomaly. It is clear from the lower left panel of Fig. 6 that the model's diurnal cycle of convection is stronger in than observed, and the duration of the diagnostic convective ice flux, present only when the deep convection parameterization is active, is limited, leading to the distinct separation of ice water content maxima in time.

\subsubsection{DC systems propagation}

We have seen in many of the upper-tropospheric variables a distinct movement of the DC systems' anomaly, within the Eulerian framework, throughout the composite period. Previous studies have identified this propagation as being associated with equatorially-trapped waves, mainly Kelvin and equatorial Rossby waves. These waves are excited by DC systems and their interaction contributes directly to the observed atmospheric variability in tropics (Žagar et al., 2004; Bechtold et al., 2008). Tropical waves propagate zonally with time, but their interaction with tropical convection is complex (Wheeler and Kiladis, 1999; Hendon and Wheeler, 2008, and references therein). While Kelvin waves propagate eastward, equatorial Rossby waves move in the opposite direction and tend to be the slower moving of the two. A robust investigation of the interaction of equatorially trapped waves and convection is beyond the scope of this study; therefore, these waves will be mentioned only in relationship to the "propagation", defined as the net movement with time of the local maximum rain rate.

In the observations, the motion is distinctly westward, indicating interaction with equatorial Rossby waves. However, the zonal elongation of the anomaly, seen in Fig. 4 (top-most panel), suggests that some DC systems also move eastward, even though these are few and do not seem to be the most intense. The nature of the compositing technique results in a shifting of the local maximum RR in the direction the majority of the DC systems moved. One method to better highlight the statistical motion of the DC systems is the use of a timelongitude plot of the DC system composite mean. The results are depicted in Fig. 7.

Two major points are seen in Fig. 7. The first is the obvious westward motion of the precipitation maximum with time in the observations (dashed red line), but an eastward propagation in the model (dashed black line). The model does seem to show some precipitation "tracking" westward (dashed red line) in a similar direction as observed, but the eastward propagation of DC systems is clearly dominant. This suggests that precipitation propagation associated with Kelvin waves are dominating in the model while equatorial Rossby waves are dominating in the observations. Also, the model seems to trigger precipitation earlier than in the observations. This can be seen in the right panel of Fig. 7 as EC-Earth appears to initiate precipitation simultaneously across a broad region. In the TMPA dataset, the precipitation is more focused and initiates about $3 \mathrm{~h}$ prior to peak convection. The second point is the diurnal cycle of the precipitation anomaly, which is stronger in the model than in the observations. In addition, there is a slow westward progression of the diurnal anomalies 


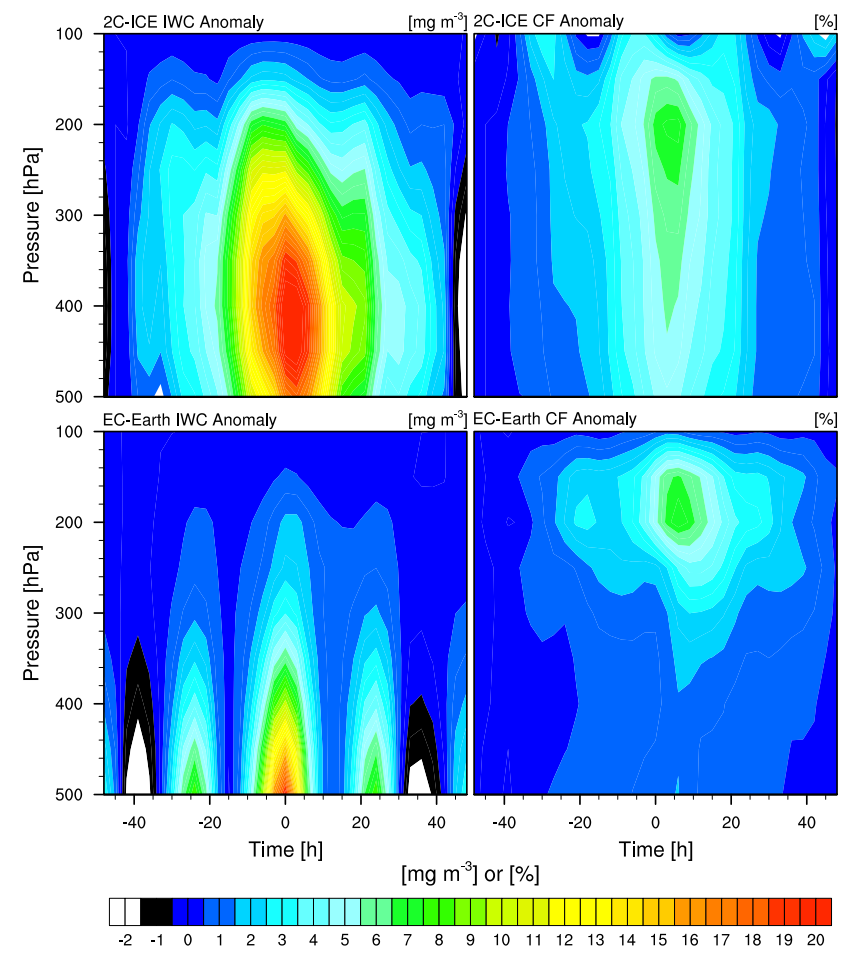

Fig. 6. Observed (top row) and modelled (bottom row) anomalies in (left column) IWC and (right column) CF, averaged over a region spanning $\pm 3^{\circ}$ latitude and $\pm 10.5^{\circ}$ longitude of the composite centre point. The background state is computed in the same manner as Fig. 5. The 2C-ICE plots are smoothed used a running mean window of $12 \mathrm{~h}$.

in the model (dashed orange line), which is not apparent in the TMPA dataset.

\section{Summary and conclusion}

Evaluation and continued development of climate models require novel approaches for confronting GCM output with observations, especially at the process level. It has already been shown that models can have, for example, global means that agree well with observations due to compensating errors (Stephens et al., 2010; Waliser et al., 2011). It is therefore essential to establish whether the model representation of key physical processes is correct and evaluate different parts of the model with different evaluation techniques.

The use of multiple satellite sensors for GCM evaluation gives us the opportunity to try to answer more questions about moist and in-cloud processes, particularly in the upper troposphere. In this study, one methodology for examining the evolution of DC systems is modified and applied to a climate model. Tropical deep convection is the main focus, but the method should be applicable to all convection of a localised nature.
The ZH09 study has been improved by expanding the filtering of DC systems to the time dimension, which reduces multiple sampling of a single event but unfortunately exposes the method's vulnerability to aliasing effects, especially when relying on single Sun-synchronous satellites such as CloudSat. This problem can be addressed by using datasets consisting of data from multiple satellites, such as the AMSU dataset. Unlike in ZH09, the background state is computed from the first 4 time bins, $-48 \mathrm{~h}$ to $-39 \mathrm{~h}$. We would remind the reader that some averages discussed here are averages of the composite mean taken over more focused regions relative to the DC systems' centre. This is done to better highlight features of the convective core. Anomaly averages are calculated using $\pm 6.5^{\circ}$ latitude and $\pm 10.5^{\circ}$ longitude for Fig. 5 and $\pm 3^{\circ}$ latitude and $\pm 10.5^{\circ}$ longitude for Fig. 6.

The observed DC systems move westward at about $4 \mathrm{~m} \mathrm{~s}^{-1}$ on average. DC systems humidify the upper troposphere, causing an increase in $\mathrm{RH}$ that peaks around 20 percentage points above background levels locally (Fig. 4). Elevated UTH persist for at least $48 \mathrm{~h}$ following peak convection. Values of UTH and OLR cover a large horizontal area that broadens after peak convection. The albedo anomaly shows significantly narrower horizontal extent than both the OLR and UTH. A maximum in the cloud fraction anomaly $(\sim 7$ percentage points) is reached between 500 and $150 \mathrm{hPa}$ at around $5 \mathrm{~h}$ and the anomaly, in total, persists for over $50 \mathrm{~h}$. For cloud ice water content, a maximum $\sim 20 \mathrm{mg} \mathrm{m}^{-3}$, is concentrated around $0 \mathrm{~h}$ and at levels close to $450 \mathrm{hPa}$.

The diagnosis of convection in EC-Earth shows that, despite some differences, the model is able to capture the essential signatures of the DC systems' anomaly, in good agreement with the observations. The upper-tropospheric humidity anomaly $\left(\% \mathrm{RH}_{\mathrm{i}}\right)$ peaks about the same time as the AMSU dataset and indicates a similar $\sim 2$ percentage point maximum. However, when looking at the composite means, the humidity can rise above $80 \%$ locally, which is $\sim 10$ percentage points above the observations.

The model's mean and anomalous OLR are in good agreement with the observations. The albedo anomaly also follows the general pattern of the observations, but its magnitude is significantly underestimated. The upper-tropospheric effects of convection in the model last about $24 \mathrm{~h}$, but the convective precipitation core does not last as long as in the observations and the model has a more pronounced repetition in the precipitation pattern. The model under-represents cloud fraction at pressure levels $>350 \mathrm{hPa}$. This is at least partially because the observations include cloud ice particles and precipitating hydrometeors, whereas the model cloud fraction does not include the contribution from precipitating stratiform or convective snow. The vertical profile of the model's cloud fraction anomaly indicates that most of the clouds generated by its DC systems are concentrated at pressures $\leq 300 \mathrm{hPa}$ and persist longer than $48 \mathrm{~h}$ in total. The cloud ice water content anomaly in the model is similar to the observations but 

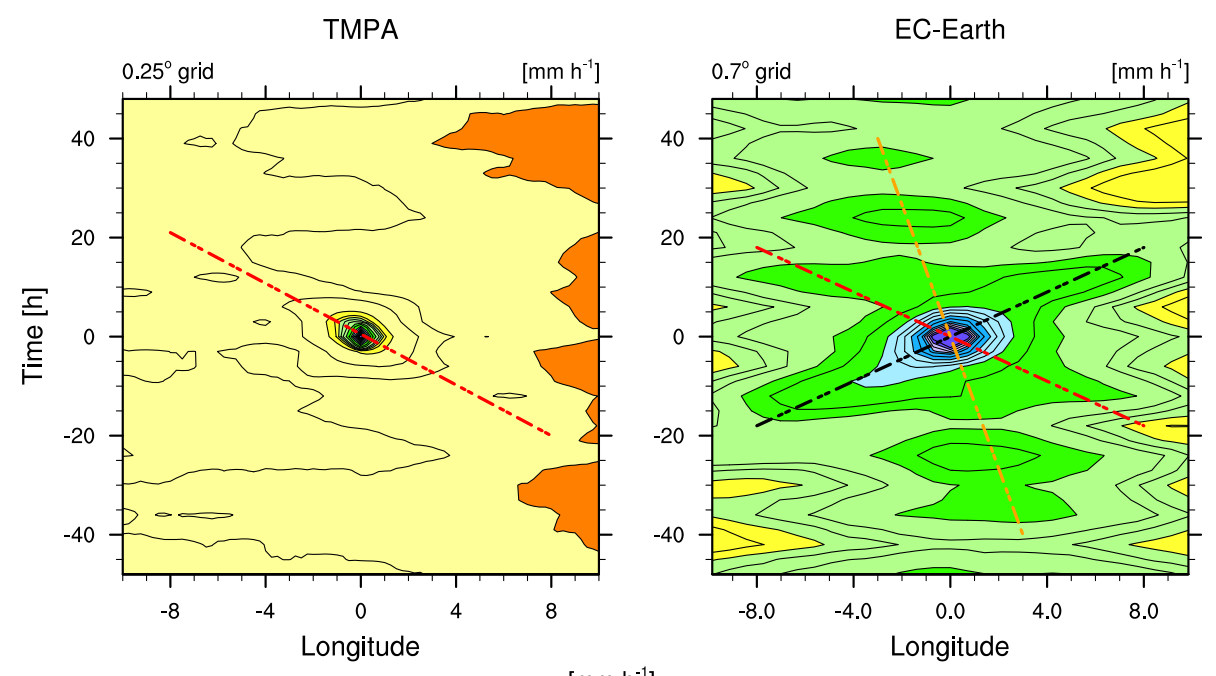

$\left[\mathrm{mm} \mathrm{h}^{-1}\right]$

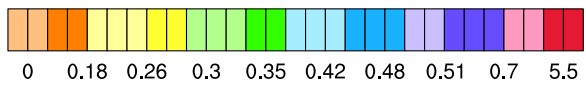

Fig. 7. Hovmöller diagrams of RR centred on composite DC systems, for (left) TMPA observations and (right) EC-Earth simulations. The lines drawn on the figures are visual aids indicating the various directions of motion discussed in the text.

is spatially much smaller, as the model's maximum can be found at pressure levels greater than $500 \mathrm{hPa}$, whereas the observations' maximum anomaly occurs from about 350 to $500 \mathrm{hPa}$.

The propagation in the composite mean of the DC systems in the model is opposite to the observations. This suggests that Kelvin waves interact more with DC systems in the model, thereby creating the appearance of an eastward movement. Figure 7 shows that the model initiates convection early across a broad region, $\sim 16^{\circ}$ longitude, focuses the convection area as time approaches peak convection, and then relaxes the precipitation again across a similarly broad area. Furthermore, the model triggers new convection in a manner that places the next event more to the west than the previous. Finally, precipitation in the observations is much more localised than in the model.

The extension of the ZH09 methodology to a climate model enables one to deduce the mean atmospheric response to convection. For example, the mean horizontal extent of anomalies and their magnitude can be ascertained and are directly comparable with satellite estimates. However, direct objective analysis of the model anomalies is hampered by oscillatory patterns in the time series of many of the variables. Nevertheless, this study can be compared to the seasonal averages of, for example, layered cloud fraction over the western Pacific (e.g. Johnston et al., 2012, Fig. 4), or temporally averaged OLR as in Waliser et al. (e.g. 2011, Fig. 2b). While these figures can highlight regions where the model and observations disagree, they do not point to an underlying cause. The compositing method discussed in this study brings the evaluation process a step closer to the model's internal pro- cess, which must first agree with observations in order to increase model fidelity.

This study is a demonstration of the use of compositing satellite data of DC systems from polar orbiting sensors for evaluation of climate models. Much more can be done with this technique, such as employing the use of satellite simulators and a more thorough investigation of the interaction between equatorially trapped waves and DC systems. These issues, along with application of the methodology to other climate models, and other regions, will be the topic of Part 2.

Acknowledgements. The authors would like to thank JeanJacques Morcrette and Peter Bechtold from the European Centre for Medium-Range Weather Forecasts (ECMWF), Martin Evaldsson (Swedish Meteorological and Hydrological Institute, SMHI), Andreas Skyman, and Ole-Martin Christensen for their technical and scientific help with this study. The authors would also like to thank Stefan Buehler at Luleå University of Technology for his input on the UTH retrievals and satellite sampling. The TMPA data were provided by the NASA/Goddard Space Flight Center's Mesoscale Atmospheric Processes Laboratory and PPS, which develop and compute the TMPA as a contribution to TRMM. In addition the CERES data were obtained from the NASA Langley Research Center Atmospheric Science Data Center. Also we would like to acknowledge the NASA CloudSat project that provided the CloudSat-CALIPSO dataset used in this project. The contribution of Mark D. Zelinka was performed under the auspices of the US Department of Energy (DOE) by Lawrence Livermore National Laboratory (LLNL) under contract DE-AC52-07NA27344 and was supported by the LLNL Institutional Postdoctoral Program and by the Regional and Global Climate Modeling Program of the Office of Science at the DOE. Salomon Eliasson and Patrick Eriksson were supported by the Swedish National Space Board. 
Finally, the authors would like to thank the anonymous reviewers and Benjamin Grandey for their critique and comments that significantly contributed in improving this paper.

Edited by: J. Quaas

\section{References}

Alcala, C. M. and Dessler, A. E.: Observations of deep convection in the tropics using the Tropical Rainfall Measuring Mission (TRMM) precipitation radar, J. Geophys. Res., 107, 4792, doi:10.1029/2002JD002457, 2002.

Bechtold, P., Chaboureau, J. P., Beljaars, A., Betts, A. K., Köhler, M., Miller, M., and Redelsperger, J. L.: The simulation of the diurnal cycle of convective precipitation over land in a global model, Q. J. R. Meteorol. Soc., 130, 3119-3137, doi:10.1256/qj.03.103, 2004.

Bechtold, P., Köhler, M., Jung, T., Doblas-Reyes, F., Leutbecher, M., Rodwell, M. J., Vitart, F., and Balsamo, G.: Advances in simulating atmospheric variability with the ECMWF model: From synoptic to decadal time-scales, Q. J. R. Meteorol. Soc., 134, 1337-1351, doi:10.1002/qj.289, 2008.

Bodas-Salcedo, A., Webb, M. J., Brooks, M. E., Ringer, M. A., Williams, K. D., Milton, S. F., and Wilson, D. R.: Evaluating cloud systems in the Met Office global forecast model using simulated CloudSat radar reflectivities, J. Geophys. Res., 113, doi:10.1029/2007JD009620, 2008.

Buehler, S. A. and John, V. O.: A simple method to relate microwave radiances to upper tropospheric humidity, J. Geophys. Res., 110, D02110, doi:10.1029/2004JD005111, 2005.

Buehler, S. A., Kuvatov, M., Sreerekha, T. R., John, V. O., Rydberg, B., Eriksson, P., and Notholt, J.: A cloud filtering method for microwave upper tropospheric humidity measurements, Atmos. Chem. Phys., 7, 5531-5542, doi:10.5194/acp-7-5531-2007, 2007.

Chen, S., Houze, R., and Mapes, B.: Multiscale variability of deep convection in relation to large-scale circulation in TOGA COARE, J. Atmos. Sci., 53, 1380-1409, 1996.

Chen, S. S. and Houze, R. A.: Diurnal variation and lifecycle of deep convective systems over the tropical $\mathrm{Pa}$ cific warm pool, Q. J. Roy. Meteorol. Soc., 123, 357-388, doi:10.1002/qj.49712353806, 1997.

Chen, W.-T., Woods, C. P., Li, J.-L. F., Waliser, D. E., Chern, J.-D., Tao, W.-K., Jiang, J. H., and Tompkins, A. M.: Partitioning CloudSat ice water content for comparison with uppertropospheric ice in global atmospheric models, J. Geophys. Res., 116, doi:10.1029/2010JD015179, 2011.

Eriksson, P., Rydberg, B., Johnston, M., Murtagh, D. P., Struthers, H., Ferrachat, S., and Lohmann, U.: Diurnal variations of humidity and ice water content in the tropical upper troposphere, Atmos. Chem. Phys., 10, 11519-11533, doi:10.5194/acp-1011519-2010, 2010.

Field, P. R. and Wood, R.: Precipitation and cloud structure in midlatitude cyclones, J. Clim., 20, 233-254, doi:10.1175/JCLI3998.1, 2007.

Forbes, R. M., Tompkins, A. M., and Untch, A.: A new prognostic bulk microphysics scheme for the IFS, ECMWF Technical Memoranda 649, European Centre for Medium-Range Weather Forecast, http://www.ecmwf.int/publications, 2011.
Gerard, L., Piriou, J.-M., Brožková, R., Geleyn, J.-F., and Banciu, D.: Cloud and precipitation parameterization in a meso-gammascale operational weather prediction model, Mon. Weather Rev., 137, 3960-3977, doi:10.1175/2009MWR2750.1, 2009.

Hendon, H. H. and Wheeler, M. C.: Some space-time spectral analyses of tropical convection and planetary-scale waves, J. Atmos. Sci., 65, 2936-2948, doi:10.1175/2008JAS2675.1, 2008.

Horváth, Á. and Soden, B. J.: Lagrangian diagnostics of tropical deep convection and its effect upon upper-tropospheric humidity, J. Clim., 21, 1013-1028, doi:10.1175/2007JCLI1786.1, 2008.

Huffman, G. J., Bolvin, D. T., Nelkin, E. J., Wolff, D. B., Adler, R. F., Gu, G., Hong, Y., Bowman, K. P., and Stocker, E. F.: The TRMM multisatellite precipitation analysis (TMPA): quasiglobal, multiyear, combined-sensor precipitation estimates at fine scales, J. Hydrometeorol., 8, 38-55, doi:10.1175/JHM560.1, 2007.

John, V. O., Holl, G., Allan, R. P., Buehler, S. A., Parker, D. E., and Soden, B. J.: Clear-sky biases in satellite infrared estimates of upper tropospheric humidity and its trends, J. Geophys. Res., 116, D14108, doi:10.1029/2010JD015355, 2011.

John, V. O., Holl, G., Atkinson, N., and Buehler, S. A.: Monitoring scan asymmetry of microwave humidity sounding channels using simultaneous all angle collocations (SAACs), J. Geophys. Res. Atm., 118, 1536-1545, doi:10.1002/jgrd.50154, 2013.

Johnston, M. S., Eriksson, P., Eliasson, S., Jones, C. G., Forbes, R. M., and Murtagh, D. P.: The representation of tropical upper tropospheric water in EC Earth V2, Clim. Dyn., 39, 2713-2731, doi:10.1007/s00382-012-1511-0, 2012.

Kirk-Davidoff, D. B., Goody, R. M., and Anderson, J. G.: Analysis of sampling errors for climate monitoring satellites, J. Clim., 18, 810-822, doi:10.1175/JCLI-3301.1, 2005.

Klein, S. A., Zhang, Y., Zelinka, M. D., Pincus, R., Boyle, J., and Gleckler, P. J.: Are climate model simulations of clouds improving? An evaluation using the ISCCP simulator, J. Geophys. Res.Atmos., 118, 1329-1342, doi:10.1002/jgrd.50141, 2013.

Liang, C., Eldering, A., Gettelman, A., Tian, B., Wong, S., Fetzer, E., and Liou, K.: Record of tropical interannual variability of temperature and water vapor from a combined AIRS-MLS data set, J. Geophys. Res., 116, D06103, doi:10.1029/2010JD014841, 2011.

Lin, J.-L., Lee, M.-I., Kim, D., Kang, I.-S., and Frierson, D. M. W.: The Impacts of Convective Parameterization and Moisture Triggering on AGCM-Simulated Convectively Coupled Equatorial Waves, J. Clim., 21, 883-909, doi:10.1175/2007JCLI1790.1, 2008.

Loeb, N. G., Wielicki, B. A., Doelling, D. R., Smith, G. L., Keyes, D. F., Kato, S., Manalo-Smith, N., and Wong, T.: Toward optimal closure of the Earth's top-of-atmosphere radiation budget, J. Clim., 22, 748-766, doi:10.1175/2008JCLI2637.1, 2009.

Luo, Z. and Rossow, W. B.: Characterizing tropical cirrus life cycle, evolution, and interaction with upper-tropospheric water vapor using Lagrangian trajectory analysis of satellite observations, J. Clim., 17, 4541-4563, 2004.

Mapes, B. E. and Houze, R. A.: Cloud Clusters and Superclusters over the Oceanic Warm Pool, Mon. Weather Rev., 121, 1398-1416, doi:10.1175/15200493(1993)121<1398:CCASOT>2.0.CO;2, 1993. 
Nam, C., Bony, S., Dufresne, J.-L., and Chepfer, H.: The 'too few, too bright' tropical low-cloud problem in CMIP5 models, Geophys. Res. Lett., 39, doi:10.1029/2012GL053421, 2012.

Nesbitt, S. W. and Zipser, E. J.: The diurnal cycle of rainfall and convective intensity according to three years of TRMM measurements, J. Clim., 16, 1456-1475, doi:10.1175/1520-044216.10.1456, 2003.

Qian, Y., Long, C. N., Wang, H., Comstock, J. M., McFarlane, S. A., and Xie, S.: Evaluation of cloud fraction and its radiative effect simulated by IPCC AR4 global models against ARM surface observations, Atmos. Chem. Phys., 12, 1785-1810, doi:10.5194/acp-12-1785-2012, 2012.

Reed, R. J. and Recker, E. E.: Structure and properties of synoptic-scale wave disturbances in the equatorial western pacific, J. Atmos. Sci., 28, 1117-1133, doi:10.1175/15200469(1971)028<1117:SAPOSS>2.0.CO;2, 1971.

Soden, B. J.: The diurnal cycle of convection, clouds, and water vapor in the tropical upper troposphere, Geophys. Res. Lett., 27 , 2173-2176, doi:10.1029/2000GL011436, 2000.

Soden, B. J.: The impact of tropical convection and cirrus an upper tropospheric humidity: A Lagrangian analysis of satellite measurements, Geophys. Res. Lett., 31, L20104, doi:10.1029/2004GL020980, 2004.

Stephens, G. L., Vane, D. G., Boain, R. J., Mace, G. G., Sassen, K., Wang, Z., Illingworth, A. J., O'Connor, E. J., Rossow, W. B., Durden, S. L., Miller, S. D., Austin, R. T., Benedetti, A., Mitrescu, C., and CloudSat Science Team, T.: The CloudSat mission and the A-Train, B. Am. Met. Soc., 83, 1771-1790, doi:10.1175/BAMS-83-12-1771, 2002.

Stephens, G. L., L'Ecuyer, T., Forbes, R., Gettlemen, A., Golaz, J.C., Bodas-Salcedo, A., Suzuki, K., Gabriel, P., and Haynes, J.: Dreary state of precipitation in global models, J. Geophys. Res., 115, D24211, doi:10.1029/2010JD014532, 2010.

Tian, B., Soden, B. J., and Wu, X.: Diurnal cycle of convection, clouds, and water vapor in the tropical upper troposphere: Satellites versus a general circulation model, J. Geophys. Res., 109, doi:10.1029/2003JD004117, 2004.

Tiedtke, M.: A Comprehensive Mass Flux Scheme for $\mathrm{Cu}$ mulus Parameterization in Large-Scale Models, Mon. Weather Rev., 117, 1779-1800, doi:10.1175/15200493(1989)117<1779:ACMFSF>2.0.CO;2, 1989.
Tiedtke, M.: Representation of clouds in large-scale models, Mon. Wea. Rev., 121, 3040-3061, doi:10.1175/15200493(1993)121<3040:ROCILS>2.0.CO;2, 1993.

Waliser, D. E., Li, J.-L. F., L'Ecuyer, T. S., and Chen, W.-T.: The impact of precipitating ice and snow on the radiation balance in global climate models, Geophys. Res. Lett., 38, doi:10.1029/2010GL046478, 2011.

Webster, P. J., Clayson, C. A., and Curry, J. A.: Clouds, Radiation, and the Diurnal Cycle of Sea Surface Temperature in the Tropical Western Pacific, J. Clim., 9, 1712-1730, doi:10.1175/15200442(1996)009<1712:CRATDC>2.0.CO;2, 1996.

Wheeler, M. and Kiladis, G. N.: Convectively Coupled Equatorial Waves: Analysis of Clouds and Temperature in the Wavenumber-Frequency Domain, J. Atmos. Sci., 56, 374-399, doi:10.1175/1520-0469(1999)056<0374:CCEWAO>2.0.CO;2, 1999.

Wielicki, B. A., Barkstrom, B. R., Harrison, E. F., Lee, R. B., Smith, G. L., and Cooper, J. E.: Clouds and the Earth's Radiant Energy System CERES: An earth observing system experiment, B. Am. Met. Soc., 77, 853-868, doi:10.1175/15200477(1996)077<0853:CATERE>2.0.CO;2, 1996.

Winker, D. M., Hunt, W. H., and McGill, M. J.: Initial performance assessment of CALIOP, Geophys. Res. Lett., 34, L19803, doi:10.1029/2007GL030135, 2007.

Wright, J. S., Fu, R., and Heymsfield, A. J.: A statistical analysis of the influence of deep convection on water vapor variability in the tropical upper troposphere, Atmos. Chem. Phys., 9, 5847-5864, doi:10.5194/acp-9-5847-2009, 2009.

Žagar, N., Gustafsson, N., and Källén, E.: Variational data assimilation in the tropics: The impact of a background-error constraint, Q. J. R. Meteorol. Soc., 130, 103-125, doi:10.1256/qj.03.13, 2004.

Zelinka, M. D. and Hartmann, D. L.: Response of humidity and clouds to tropical deep convection, J. Clim., 22, 2389-2404, doi:10.1175/2008JCLI2452.1, 2009. 